\title{
Chain migration and residential segregation of internal migrants in the metropolitan area of São Paulo, Brazil
}

\author{
Emily Skop \\ The University of Texas at Austin \\ eskop@prc.utexas.edu \\ Paul A. Peters \\ The University of Texas at Austin \\ papeters@prc.utexas.edu \\ Ernesto F. L. Amaral \\ The University of Texas at Austin \\ eflamaral@gmail.com \\ Joseph E. Potter \\ The University of Texas at Austin \\ joe@prc.utexas.edu \\ Wilson Fusco \\ Universidade Estadual de Campinas, Brazil \\ wfusco@prc.utexas.edu
}

\begin{abstract}
This paper focuses on the geography of internal migration to and settlement within the metropolitan area of São Paulo. Specifically, the research objectives are to: (1) document the major flows of internal migration into the São Paulo metropolitan area; (2) map both short- and long-term migrant patterns of settlement within the São Paulo metropolitan area; and (3) approximate to what extent particular migrants from specific sending areas spatially concentrate in certain neighborhoods within the metropolitan area using both non-spatial and spatial measures of segregation. The key feature of our theoretical argument is that migrant networks evolve, accumulate, and generate higher than expected levels of internal migration to particular neighborhoods. As internal migrants become increasingly concentrated and a dynamic feedback process emerges between origin and destination, the metropolis becomes both segmented and segregated.
\end{abstract}

\section{Keywords}

Internal migration. Social networks. São Paulo. Brazil.

\section{Acknowledgments}

This research was supported by a "Center for the Study of Urbanization and Internal Migration in Developing Countries" grant from the Mellon Foundation to the Population Research Center at the University of Texas at Austin. This is a revision of a paper presented at the Annual Meeting of the Association of American Geographers, Denver, Colorado, April 2005.

\section{Final publication}

Skop E, Peters PA, Amaral EFL, Potter JE, Fusco W. 2006. "Chain migration and residential segregation of internal migrants in the metropolitan area of São Paulo, Brazil." Urban

Geography, 27(5): 397-421. 


\section{Introduction}

During the last 50 years, the process of urbanization in Brazil has been remarkable. Post-war government policies that stimulated economic growth, along with private industrial and commercial expansion, have prompted dramatic flows of migration from the countryside to Brazil's large and intermediate sized cities. From the early 1950s onward, deteriorating economic, social, and environmental conditions in many parts of rural Brazil triggered growth in urban places. Large numbers of rural migrants from all parts of the country (but particularly from the most poverty stricken states in the Northeast) used improved roads and expanding transportation networks to enter Brazil's cities. By the 1970s, a fully integrated socio-spatial system ensured the process of rural-to-urban and urban-to-urban migration in Brazil. Even as the country started to experience serious economic difficulties and the pace of urbanization declined between 1975 and 2000, internal migration continued to be an important, dynamic phenomenon. While in 1950, less than 40 percent of Brazil's population lived in urban locales, today more than 81 percent of Brazilians reside in a metropolitan area.

This powerful process of internal migration has guaranteed the constant transformation of urban Brazil's social, political, cultural, and economic landscapes. Unfortunately, there is very little empirical research examining the socio-spatial impacts of internal migrants within various metropolitan settings. While detailed ethnographies and community studies describe the ways in which internal migrants from particular sending areas are funneled to certain neighborhoods within the city, no broad-scale urban spatial analysis exists. This paper bridges theoretical and empirical gaps in the 
literature and provides the first mesoregion-wide examination of internal migration settlement patterns using detailed sample data released from the 2000 Brazilian

Census. Utilizing Geographic Information Systems (GIS) techniques, the paper focuses on the geography of internal migration to and settlement within the mesoregion of São Paulo.' Specifically, the research objectives are to:

(1) Document and map the newcomers' patterns of settlement within the São Paulo mesoregion;

(2) Approximate to what extent social networks and chain migration prompt particular migrants to spatially concentrate in certain neighborhoods within the mesoregion area; and

(3) Apply non-spatial and spatial measures of segregation to determine the extent to which internal migrants are concentrated within the mesoregion.

The key feature of our theoretical argument is that migrant networks can evolve, accumulate, and generate higher than expected levels of internal migration to particular neighborhoods within the city. As internal migrants become increasingly concentrated and a dynamic feedback process emerges between origin and destination, the metropolis becomes rapidly segmented and highly segregated. 


\section{The segmented metropolis}

The international migration literature is rich with evidence of the significant role of chain migration and social networks in creating segmented cities where local neighborhoods can be defined along national lines. Various theoretical perspectives in urban ecology describe the process of immigrant spatial succession and assimilation, and its role in the development of the metropolis (Park, Burgess, and McKenzie 1925; Philpott 1978; Massey and Mullan 1984; Alba and Logan 1991; White, Dymowski, and Wang 1994; and Allen and Turner 1996a). The enduring Chicago School model suggests that, upon entry, new arrivals settle in central city ethnic enclaves to save transportation costs, locate near employment opportunities, access the cheapest housing, and gain support from ethnic networks. A pattern of chain migration ensues as new arrivals, with connections to immigrants already living in the area, come into the neighborhoods upon entry. The continued infusion of new immigrants ensures the relative homogeneity of ethnic neighborhoods - and the creation of communities established along ethnic lines (Pacyga 1995, 611).

Scholars contend that the more linkages that connect individual migrants, the greater the spatial density within particular urban communities. History has shown, especially in the case of international migration, that strong social networks and chain migration often become important facilitators in the process of residential concentration and segregation. Various types of social networks play a significant role in shaping exactly where migrants put down roots within a city. Many immigrant groups in the US, for instance, have exhibited social solidarity through highly organized spatial arrangements 
- Chinatown, Little Italy, and Greektown come to mind. These delineated spaces serve a variety of functions for newcomers and old-time settlers alike and continuously concentrate residents, businesses, and places of worship within a particular neighborhood or area of the city (Abrahamson 1996).

Certainly, a great deal of scholarly attention has been paid by social scientists to analyzing the role of social networks in shaping and reshaping urban immigrant enclaves, especially in the United States (Portes and Jensen 1987; Zhou and Logan 1991; and Li 1998). These works demonstrates the web of social connections that are particularly helpful, and sometimes essential, in pooling international immigrants together into particular spatial clustering. The idea of cumulative causation, in particular, suggests that each additional migrant within a stream increases the propensity for others to migrate in that same channel, thus creating high levels of international migration to specific destinations (Massey 1990; and Massey and Zenteno 1999). Early migrants reduce costs and risks for later arrivals; as knowledge and experience accumulates with each trip, more potential migrants are induced to move, further expanding the network, and creating increasingly developed paths of migration between particular origins and destinations. In other words, the process of migration becomes self-perpetuating as social networks connect migrants to non-migrants, thereby increasing movement along specific routes.

Whether these ideas can be translated to patterns of internal migration in the Latin America case is a critical question. Some work explicates the functions of social networks 
in patterns of internal migration in the developing world context, particularly from rural-tourban settings (Hugo 1981; Instituto de Geografia 1988; De la Paz Lopez 1993;

Kanaiupuni 2000; Cunha 2001; and Curran et al. 2003). But the research tends to focus primarily on patterns of internal migration at the state- and mesoregion-level, often with particular attention to evaluating the gendered content of migration networks. With the exception of a few early studies of Mexico City (Browning 1971; and Cornelius 1975), a gap remains in understanding how the process of internal migration creates highly dynamic and concentrated patterns of residential segregation within metropolitan areas. Yet, it is clear from both detailed ethnographies and community studies, along with accounts in the popular press, that internal migrants from particular sending areas are not only funneled to certain metropolises, but that they are even further channeled to specific neighborhoods within the city.

\section{Research objectives}

This paper seeks to determine whether internal migrants to São Paulo, Brazil cluster to the same extent as international migrants concentrate in other contexts. In other words, what are the residential geographies of Brazilian internal migrants? Of particular interest in this paper is articulating whether social networks prompt migrants to settle in particular areas within the city. The analysis links individual-level migration data from the census to geographic conditions to assess the location and composition of Brazilian internal migrants within the São Paulo Mesoregion. We suggest that: 
1. Long-term internal migrants (those that have been living in the city for 10 years or longer) are more likely to be living in more centralized neighborhoods, whereas shortterm migrants (those that have been living in the city for 9 years or less) are more likely to be residing on the periphery of the city. This patterning is largely a result of the transformation of the urban environment, and the expansion of cheaper housing, transportation links, and job prospects in outlying areas, which creates new opportunities for recent migrants.

2. Internal migrants from areas with well-known, long-established links between origin and destination are likely to be more dispersed in the mesoregion. These migrants have more knowledge of, and experience within, the city. As a result, they are more likely to be aware of the costs and benefits of living in particular neighborhoods, and have a level of choice unavailable to those migrants with less-established social networks. Migrants from Bahia and Minas Gerais, states with long and sizeable records of migration to São Paulo, will be more dispersed than migrants from Piauí, another Northeast state with much smaller flows and a shorter history of migration to the metro area.

3. Internal migrants to São Paulo demonstrate low levels of segregation in the mesoregion, according to standard measures. This is not because the migrants do not cluster in particular neighborhoods; rather it is a function of vulnerability of the geographical unit of analysis and sampling variation in the dataset, which limits the degree to which traditional indices of dissimilarity are able to capture any amount of 
unevenness and/or concentration. Still, patterns of clustering do appear, and these patterns indicate that social networks are operating to concentrate particular groups in particular areas.

\section{Data and measurement}

\section{Data}

The paper uses newly released micro-data from the 2000 Brazilian census to examine the degree to which individual migrants from specific states and municipalities within Brazil tend to live together in particular neighborhoods in São Paulo. The latest census data has been released in a way that permits the examination of individual records from a long-form questionnaire distributed to ten percent (10\%) of the population. The data includes geo-coded, detailed individual sample records with specifics on birthplace, migration, occupation, and many other socioeconomic and demographic characteristics.

Importantly, the sample provides a description of geographical mobility and resulting redistribution of sampled individuals across states, counties, and meso-regions. In all, the 2000 Brazilian Census has thirteen (13) questions related to migration. There is information about an individual's state or country of birth, the time of uninterrupted residence in the present city and state, the state of previous residence, the type of residence exactly five years before the census (urban or rural area), and the municipality and state of residence five years before the census. 
For this paper, we utilized several of the available migration questions to perform two different tasks: 1) to classify migrants based on state of origin and length of residence; and 2) to characterize migrants based on municipality of origin. In the first step, information about state of birth and time of uninterrupted residence in the city were utilized to categorize migrants by state of origin. Those persons born in the city of São Paulo are non-migrants. All other individuals were divided into two other "migrant" categories. Short-term migrants are those that were not born in the city of São Paulo and who have lived in the city less than ten years. Long-term migrants were not born in the city of São Paulo but have lived in the city for ten years or more.

In the second step, the municipality and state of residence five years before the census were used to capture the importance of specific sending municipalities in internal migration flows to particular neighborhoods within São Paulo. Here, we took the 10 most significant municipal flows from each state as a proportion of the sending population rather than the absolute count of migrants. In this way, we sought to more specifically articulate the role of social networks in determining settlement patterns.

There is a final important note about the geography of our analysis. For the first time, the 2000 Brazilian Census provides information about individuals at a particularly fine-scale, what the census documentation calls areas de ponderaçao (or as we will refer to them, "AP's"). Census enumerators and local officials created these AP's to accurately capture particular and well-defined neighborhoods within the mesoregion. AP's are the smallest functional units for geographic analysis within the mesoregion available with the $10 \%$ 
sample, as well as being the smallest spatial unit available in this dataset. In all, there are 882 AP's within the São Paulo mesoregion (with a total population of 19,198,273 residents). The range of weighted individuals within each AP varies considerably, from less than 8,000 to more than 100,000 persons. The average AP contains approximately 800 households - or 22,000 individuals. The spatial boundaries of each AP within the São Paulo mesoregion are provided by the Brazilian census and are utilized in a Geographic Information System (GIS) analysis to capture patterns of residential concentration and the spatial clustering of internal migrants.

\section{Measurement}

Maps are powerful tools that create visible, descriptive records of migrant settlement and migrant neighborhoods. As a result, the analysis begins by mapping 1) the major flows of internal migration into the São Paulo mesoregion; 2) the spatial distribution of long-term and short-term migrants by source state; and 3) the spatial patterning of 5-

year migrants by municipality of origin and AP of destination. Each of these exercises is an attempt to articulate whether there is any significant clustering of groups by AP. The results are mixed and indicate considerable variation by origin group and by time of arrival.

The investigation continues with the most widespread measure of residential segregation - Duncan and Duncan's (1955) index of dissimilarity, commonly known as the $D$ index. This index is a summary measure of the total differences of spread of at least two different groups over all enumeration unites of the study region. In our case, 
we analyze the difference between the distributions of migrants from particular source states in Brazil (including Bahia, Alagoas, Minas Gerais, etc.) with the distribution of all migrants across individual AP's within the São Paulo mesoregion. Because the $D$ index does not articulate the spatiality of segregation patterns (indeed, it is an aspatial measure), we then introduce a succession of other spatial indices to approximately measure dimensions of exposure, interaction, centralization, and clustering. The most relevant measure is the "threshold" technique first introduced by Poulsen et al (2001). This technique creates an isolation - assimilation continuum that captures the degree to which a group shares residential areas with other groups in the mesoregion.

In a final step, we more carefully examine the municipalities in which migrants from a particular state resided five years ago. While the numbers of these migrants are not very large, they do shed light on the role of social networks and chain migration in prompting migrants from particular municipalities to spatially concentrate in certain neighborhoods within the mesoregion. We argue that if chain migration were important, we would expect to find migrants from certain source municipalities moving to particular AP's where there are already a sizeable proportion of long-term migrants from that same state. Moreover, we would expect that other migrants in other non-adjacent AP's might come from a quite different set of municipalities. 


\section{Migration patterns to São Paulo}

The mesoregion of São Paulo has seen a population explosion in the past half century, largely a result of the urbanization process, and the movement of rural Brazilians to the urban area. Today, internal migration from outside the state no longer accounts for the majority of population increase in São Paulo, as natural increase, especially in the urban core, fuels growth in the mesoregion (Cunha and Azevedo 2001). Still, the movement of Brazilians to São Paulo has had, and continues to have, a tremendous impact on the composition of the resident population. As Table 1 illustrates, of the almost twenty (20) million residents living in the mesoregion, nearly sixty-eight (68) percent were born outside of São Paulo. Just more than thirty (30) percent were born in the city. This is remarkable and points to the intense and profound role of migration in stimulating growth in the mesoregion. Forty-eight (48) percent of residents in São Paulo were not born in the city and have lived there more than 10 years. Another nearly twenty (20) percent of migrants have been living in the mesoregion less than 10 years (short-term migrants).

\section{$\gg>$ Table $1 \ll$}

While it is obvious that flows of internal migration have decreased in recent years, and uncertain economic opportunities await newcomers in the mesoregion, São Paulo continues to prompt the flow of internal migrants from all parts of Brazil. ${ }^{i i}$ As Baeninger (2001) suggests: “...in the migrant imagination, especially for those from less dynamic regions, the area continues to exert a strong attraction" (Baeninger 2001, 227). This "pull" towards São Paulo is readily apparent in the migratory behavior of short-term migrants to the mesoregion in 2000. 
Table 2 reports the absolute numbers and percentages of short-term migration flows to São Paulo.iii Movement from two northeastern states - Bahia and Pernambuco - to São Paulo is conspicuous. These two source states account for forty-four (44) percent of the short-term migration streams to São Paulo (if internal migration within the state of São Paulo is excluded). These northeastern states have long established and sizeable flows of migration to the mesoregion. Indeed, more than half (52 percent) of migrants living in the mesoregion for more than ten years also come from Bahia and Pernambuco.

\section{$\gg>$ Table $2 \ll<$}

Minas Gerais, a state directly along the northeast border of the state of São Paulo, continues to be a major supplier of migrants, accounting for nearly twelve (12) percent of the total flow of short-term migrants into the mesoregion of São Paulo (excluding internal migrants within the state). This is despite a continued and overall reduction in emigration to São Paulo from Minas Gerais since the 1990s, when the state began to retain more of its population (Cunha 2001, 257).

Other northeast states provide smaller numbers of recent migrants to the mesoregion and include Ceará, Paraíba, Alagoas, and Piauí. The relatively high levels of emigration to São Paulo (with more than 660,000 short-term migrants from these states living in mesoregion in 2000) suggest that the mesoregion continues to be an important magnet for northeasterners, despite a real reduction in both the absolute numbers and rates of in-migration, which might have been influenced by an increase in the ability of the 
Northeast's largest cities to retain their populations along with the potential intensification of return migration. This is a phenomenon Cunha (2001) noted with interstate migration data to the State of São Paulo from the 1990 census. It appears that despite an overall decline in the so-called "rural exodus", São Paulo continues to attract migrants from the Northeast, and that this flow is likely to continue into the future.

\section{$\gg>$ Figure $1 \ll$}

Figure 1 provides a visualization of major internal migration flows to the mesoregion by mapping the absolute numbers and state of origin of all migrants (i.e. both short-term and long-term migrants) living within São Paulo. There were nearly thirteen (13) million migrants residing in the city in 2000 and several major streams of internal migration are evident. The largest flow comes from within the State of São Paulo itself, with more than 3.5 million residents moving within the state at some point since they arrived. This movement makes sense given the enormous amounts of spatial redistributing that typically occurs in a mesoregion of this size and scale.

The migration patterns generally reflect the states that have been historical suppliers of migrants in the past. The state of Bahia stands out as the most prominent source of migrants outside the state of São Paulo. But migration from Minas Gerais and Pernambuco is also significant: more than 3 million migrants from these two states lived in the mesoregion of São Paulo in the 2000 census. More medium-sized flows, ranging from approximately 400,000-600,000 migrants, begin in the states of Paraná, Ceará, Paraíba, and Alagoas, and even smaller streams, from 120,000-320,000 migrants, embark from states like Piauí, Sergipe, Rio de Janeiro, Rio Grande do Norte, and 
Maranhão. The remaining Brazilian states send insignificant trickles of migrants to the mesoregion.

It is apparent that migration to São Paulo constitutes a complicated system that involves many different players and diverse types of movement. Recent urbanization processes and the spatial redistribution of population in São Paulo indicates that the mesoregion remains attractive for migratory flows, despite the evident decrease in absolute volumes and rates of in-migrants. Historic suppliers of migrants, like Bahia and Pernambuco, continue to see high levels of emigration to São Paulo, and demonstrate the affects of cumulative causation in the formation of specific and direct channels between particular sending and receiving areas.

\section{Mapping short-term versus long-term internal migrants within the metropolitan} area

The internal migrants' geography of settlement within São Paulo has been a mystery up until this point. It is only with the release of the 2000 Brazilian Census, along with advancements in Geographic Information System (GIS) tools, that analyses at the mesoregion-scale are even possible (see Ramos (2002) for another usage of GIS in mapping the urban structure of São Paulo). The ability to document and map the residential behavior of internal migrants within the mesoregion provides a much clearer picture of how the newcomers organize themselves in urban social space. This spatial project also offers an alternative method for capturing the role of social networks in channeling migrants to certain parts of the city. 
Importantly, our analysis indicates that internal migrants to São Paulo are concentrated in different parts of the mesoregion depending on their time of arrival. Figure 2 displays the total number of short-term migrants within each AP as a percent of the total population within each AP, whereas Figure 3 presents the total number of long-term migrants within each AP as a percent of the total population within each AP. Striking differences in the residential behavior of short-term versus long-term migrants are immediately apparent.

\section{$\gg>$ Figure $2<<<$}

The periphery is especially prominent as a magnet for short-term internal migrants. Few AP's in the core municipality of São Paulo boast populations of short-term migrants greater than twenty (20) percent as a percentage of the total population in the AP. In contrast, many outer AP's in São Paulo, especially in the Northwest and Northeast sectors, could be labeled "short-term migrant ghettoes" as the vast majority of residents, (between forty (40) and eighty (80) percent) in these AP's have been living in the city for less than ten years. In effect, a ring of short-term migrants appears to emerge on the outskirts of the mesoregion in 2000.

This socio-spatial pattern is largely the result of pronounced income inequality in the mesoregion; a characteristic of São Paulo that is accompanied by accentuated spatial differentiation (Jannuzzi and Jannuzzi 2002; Leme 2003; Pasternak and Baltrusis 2001; and Schor et al. 2003). Poor neighborhoods are mainly located in the peripheral regions of the city, with lower per capita incomes and quality of life that contrasts with 
some central areas that boast excellent urban facilities, more developed infrastructure, and higher per capita incomes. This general urban configuration creates a pronounced decline in land values, economic activities, and living conditions from the center towards the outskirts of the mesoregion, and highly contrasting socioeconomic situations between core and periphery.

As migrants who generally arrive in São Paulo with lesser amounts of social and economic capital, short-term migrants of the mesoregion are concentrated in the urban fringe, where they are more likely to find cheaper and more affordable housing. Indeed, many short-term migrants seek out periferias - spaces located on the fringe of the city that are predominantly produced by irregular or illegal parceling of large land holdings by private developers who do not fulfill the necessary requirements for the approval of the settlement in the municipality of governance (Torres et al. 2002).

\section{$\gg>$ Figure $3<<<$}

As Figure 3 illustrates, long-term migrants are much more dispersed throughout the entire mesoregion. They represent the majority of residents in the core, with most centralized AP's containing long-term migrant populations of forty (40) to eighty (80) percent of the total population within each AP. At the same time, many outer sectors of São Paulo also contain a majority long-term resident population. Unlike the map for short-term migrants, the long-term migrant map doesn't point to high levels of concentration in any one sector of the mesoregion, though some AP's in the Southeastern sectors of the city contain higher than expected long-term migrant 
populations (where eighty (80) percent or higher of the population has been living in the mesoregion for more than 10 years).

São Paulo, then, is saturated with migrants who have resided in the mesoregion for at least ten (10) years. This patterning has as much to do with the fact that migrants, as

stated previously, represent nearly seventy $(70)$ percent of the overall population in São Paulo, as it does with the apparent process of intra-urban mobility that facilitates dispersion and redistribution in the mesoregion. Both processes have guaranteed that São Paulo be characterized as a migrant city.

\section{The role of chain migration in creating residential clusterings}

\section{Mapping chain migration}

The affects of channelization from certain source states to particular neighborhoods within the mesoregion of São Paulo can only be explored indirectly with this dataset as we have no way to determine whether connections between different individuals and households residing in separate living units exist. Still, the role of social networks in filtering new migrants to particular areas of the mesoregion is appealing, given the ability of similar work to capture international migration trends in U.S. cities like Los Angeles, Chicago, and New York (Allen and Turner 2002; Logan, Alba, and Zhang 2002; and Ward 1968). Our idea is that there will be significant clustering of migrants by municipality of origin and AP of destination, as individual migrants are more likely to settle in areas where they know that there are other migrants from their state of origin. 
In this step, we change our reference data from classifying migrants based on state of origin and length of residence to characterizing incoming migrants based on the 5-year migration question. This census question specifies the migrant's municipality of origin, and enhances our ability to capture the ways in which specific channels of internal migration from various municipalities tend to settle in particular AP's within São Paulo. In a sense, we are bringing the "scale" of the analysis downward - from the state to the municipality - and provide a more detailed geography of settlement.

To further enhance our analysis, we have disaggregated the top ten proportional flows of migration from various municipalities in three states: Bahia, Minas Gerais, and Piauí. These three states are ideal for comparison because the absolute size of migration flows from each varies considerably. Each state, as previously demonstrated, also has a different history of internal migration to, and contemporary linkage with, the São Paulo mesoregion. As a result, it is likely that current patterns of settlement will vary considerably between all three states.

Finally, we estimate the spatial relationship between municipality of origin and AP of destination by mapping out the residential geographies of individual migrants in the mesoregion. These dot density maps demonstrate whether migrants from certain municipalities settle in the same AP's as long-term migrants from the same state. One problem with this methodology is that we have yet to develop a way to aggregate individuals within a household, thus creating the possibility that any/all the migrant dots within an AP are from the same family, and/or living in the same household. ${ }^{\text {iv }}$ Still, the 
use of dots to represent individual migrants allows us to perform analyses that at least gauge the likelihood that recent migrants are finding their way into the AP's where longterm migrants are also residing, and thus, tell us something about the role of social networks in facilitating the process of settlement in a complicated urban setting.

Figures 4,5 , and 6 reveal some interesting patterns about where migrants from the three states settle in general. First, there are obvious differences in the spatial distributions of each group. Migrants from Bahia are considerably more concentrated in the APs located on the outskirts of São Paulo, whereas those from Minas Gerais and Piaui tend to concentrate in both the core and periphery of the city. Second, while the spatial distribution of each migrant group differs, all tend to concentrate within small groupings of spatially contiguous AP's. Migrants from Piauí appear to be more randomly scattered throughout the mesoregion, with the exception of the large clustering of these migrants in the Northwest quadrant of São Paulo. Third, the maps create a definite picture regarding the ways in which new migrants become channeled to certain neighborhoods within the mesoregion. A clear spatial relationship between the municipality of origin and the AP of destination appears to exist, though the significance of the relationship has yet to be tested statistically. For migrants from Bahia, particularly, there appears to be a clear direct correlation of where new migrants are settling with where long-term migrants also reside.

>> Figures $4,5,6<<$ 


\section{Measuring residential segregation}

The above mapping exercise is an effective method that allows for the visualization of basic residential patterns of concentration and/or dispersion. But mapping gives little indication of the amount and/or nature of mixing taking place within São Paulo. Table 3 includes several indices of segregation for select migrant groups in the mesoregion. Given the complex nature of urban settlement patterns, the use of multiple indices provides a deeper understanding of the multiple dimensions of segregation. The measures chosen here are the dissimilarity, exposure, isolation, $D(s)$, and $S$ indices (Wong 2003). ${ }^{v}$

Perhaps the most notable result shown in the table is the tendency for the index to increase as the size of the migration flow diminishes. This result is, we suspect, largely due to the effect of sampling variation-the noise to signal ratio increases as the number of migrants shrink and the number of APs with either very small numbers of migrants from a given state or no migrants from that state increases. On the other hand, we believe that if one compares the indices for several states with a similar number of migrants, then the indices are informative. Thus, there appears to be a more uneven distribution of migrants from the rest of the state of São Paulo than there is for migrants from Bahia. Similarly, and more directly in line with our hypothesis regarding the influence of chain migration and social capital in clustering, there is greater segregation among migrants from the Northeastern state of Pernambuco than there is from the Southeastern state of Minas Gerais. Lastly, looking at some of the "medium" sized migration flows, the greatest clustering is to be found among migrants from "Other 
Countries", and the least among migrants from the Southern state of Paraná. We suspect that the former is due to the concentration of the former in a relatively small number of higher income or ethnic neighborhoods, while the latter is due to the difference between the process of migration from the South and that which prevails for migration from the Northeast.

\section{>> Table $3 \ll<$}

To understand the spatial patterning of internal migrants in São Paulo, another useful approach is a threshold analysis. Threshold analysis, proposed by Poulsen et al. (2001) and developed further by Johnston et al. (2002), provides a general profile for individual groups to establish whether they form a majority in any particular areas of a city and create exclusive residential districts. The technique creates an isolation assimilation continuum that captures the degree to which a group shares residential areas with other migrant groups and the overall host community.

In Table 4, we have adapted the threshold procedure to our study groups and calculated for the various types of potential residential patterning. There are three critical differences between the original threshold analysis and our own. First, in our case, internal migrants are the "unit" of analysis, whereas Poulsen et al. and Johnson et al. use ethnic groups (which are largely composed of various international migration groups but also include "native" groups like African Americans and Aborigines). Second, our thresholds are disaggregated at the AP level, whereas other analyses are able to use a much smaller geographic unit of comparison - the census tract - to calculate thresholds. Our third adaptation takes care of this aggregation to a larger 
geographic unit by lowering threshold levels because no migrant group represents more than forty (40) percent of any one AP, whereas in the other threshold analyses, census tracts can contain upwards of eighty (80) percent of any one ethnic group, not only because spatial clustering is prevalent, but also perhaps because the population within that geographic unit of analysis is smaller.

\section{$\gg>$ Table $4<<$}

The isolation - assimilation continuum originally proposed in threshold analysis does not exactly "fit" this new cultural/geographic context. The original continuum begins with the polarized enclave with one ethnic group substantially isolated and the mixed minority enclave with two or more ethnic groups sharing the same space. The multiethnic neighborhood is the most assorted community type with relatively equal numbers of both ethnic group members and the white host society. The continuum ends with the assimilated community where the white host society forms the majority and the ethnic group a significant minority and the citadel where the ethnic group is mostly absent in a majority white host society area.

Because none of the internal migrant groups fit into the extreme "ghetto" or "polarized" categories (i.e. internal migrants do not live in significantly isolated communities in São Paulo), we have reconfigured the continuum to more closely relate to the São Paulo situation. This rearrangement means that new thresholds were created and the most "isolated" thresholds include those AP's where migrants form at least thirty-five (35) to forty (40) percent of all the migrants living within an individual AP. Only one group, the migrants from Bahia, form any significant clusters at this level of concentration. 
The vast majority of migrants tend to form much smaller minorities of individual AP's. As is confirmed by the data, there are significant similarities among most of the migrant groups in São Paulo. The majority of migrants from all of the major states of inmigration live in AP's where they represent fewer than fifteen (15) percent of the total population. The migrant groups are in no way isolated from one another and/or the non-migrant population.

Still, the majority of migrants from many states (excluding Bahia, Parana, Ceará, Alagoas, and Piauí) live in AP's where they represent more than their population totals for the entire city. These are in no way "enclave" type neighborhoods, yet they do suggest some clustering along origin-state lines, especially in the case of Minas Gerais and Paraíba. This resonates with the maps presented above and field evidence presented in other research. Little Minas and Paraíbatown have yet to become conspicuously manifest in São Paulo.

Because urban growth in São Paulo has generally occurred in an informal, unorganized fashion (Aguilar and Ward 2003), the urban structure varies considerably from the North American model upon which most indices of segregation are based. Though we have partially countered for that in our new threshold analysis, much work remains to be done. One of the challenges we face in this endeavor is to develop measures of spatial distribution that are appropriate both to our hypotheses and to the stochastic nature of our data. Since the index of dissimilarity seems to be highly vulnerable to sampling variation, 
we plan to introduce new methods that take sampling variation into account (Grusky and Charles 1998).

\section{Conclusion}

Given our concern with internal migration as a geographical phenomenon, we argue for the use of a variety of mapping techniques and descriptive, spatial statistics to quantify residential segregation as a process related to social networks and chain migration. particularly with the ways in which internal migrants from particular sending areas create particular "destination" neighborhoods in São Paulo.

With these preliminary calculations and figures, we believe we have demonstrated the plausibility of the hypothesis that chain migration and social capital are responsible for some of the spatial concentration of migrants in the municipality of São Paulo. However, much remains to be done before any kind of an assessment of the relative importance of this phenomena can be reached. Fortunately, we have a great deal of data to explore and bring to bear on this project.

One task is to gauge the degree to which socioeconomic status accounts for the concentration in migrant settlement that we observe. Again, the individual long-form census records at our disposition provide a rich resource from which to draw since they contain information on education, occupation, housing quality, and a variety of consumer durables (eg. Cars and refrigerators). 
While it is commonplace to recognize the contribution of social networks to the settlement patterns of international migrants to major metropolises, when it comes to internal migration, such linkages come mostly from ethnographies. With the release of detailed geographic identifiers in the Brazilian 2000 census micro-data, we can now begin to explore this phenomenon in a more comprehensive and generalizable manner. 


\section{References}

Abrahamson, Mark. 1996. Urban enclaves: Identity and place in America. New York: St. Martin's Press.

Alba, Richard and John R. Logan. 1991. Variations on two themes: Racial and ethnic patterns in the attainment of suburban residence. Demography 28(3): 431-454.

Allen, James A. and Eugene Turner. 1996. Spatial patterns of immigrant assimilation. Professional Geographer 48(2): 140-155.

. 2002. Changing Faces, Changing Places: Mapping Southern Californians. Northridge, CA: Center for Geographical Studies.

Baeninger, Rosana. 2001. Migration and Urbanization in São Paulo: the new scenario. In Population Change in Brazil: Contemporary Perspectives, ed. Daniel Joseph Hogan: 225-253. São Paulo: Population Studies Center, NEPO/UNICAMP.

Browning, Harley L. 1971. Selectivity of migrants to a metropolis in a developing country; a Mexican case study. Austin: Institute of Latin American Studies, University of Texas at Austin.

Cornelius, Wayne A. 1975. The impact of cityward migration on urban land and housing markets: Problems and policy alternatives in Mexico City. Cambridge: Migration and Development Study Group, Center for International Studies, Massachusetts Institute of Technology.

Cunha, José Marcos Pinto da. 2001. Intraregional mobility in the context of migratory changes in Brazil between 1970 and 1991: the case of the São Paulo Mesoregion Region. In Population Change in Brazil: Contemporary Perspectives, ed. Daniel Joseph Hogan: 255-286. São Paulo: Population Studies Center, NEPO/UNICAMP.

Cunha, José Marcos Pinto da and Marta Maria Azevedo. 2001. Demographic and Socio-cultural Aspects of Population Mobility in Brazil. In Population Change in Brazil: Contemporary Perspectives, ed. Daniel Joseph Hogan: 35-49. São Paulo: Population Studies Center, NEPO/UNICAMP.

Curran, Sara R., Filiz Garip, Chang Chung, and Kanchana Tangchonlatip. 2003. Migration, Cumulative Causation, and Gender: Evidence from Thailand. Paper prepared for Conference on African Migration in Comparative Perspective. Johannesburg, South Africa. Accessed February 12, 2004. http://pum.princeton.edu/pumconference/papers/3-Curran.pdf

De la Paz Lopez, Maria, Haydea Izazola and José Gómez de León. 1993. Current Trends and Patterns of Female Migration: Evidence from Mexico." International Migration Review 27: 748-71. 
Grusky, David B., and Maria Charles. 1998. The past, present and future of sex segregation methodology. Demography 35(4): 497-504.

Hugo, Graeme. 1981. Village-Community Ties, Village Norms, and Ethnic and Social Networks: A Review of the Evidence from the Third World. In Migration Decision Making: Multidisciplinary Approaches to Microlevel Studies in Developed and Developing Countries, ed. Gordon DeJong and Robert W. Gardner: 186-225. New York: Pergamon Press.

Instituto de Geografia. 1988. Atlas de migracion interna en Mexico. Mexico: Universidad Nacional Autonoma de Mexico.

Jannuzzi, Paulo de Martino and Nicoláo Jannuzzi. 2002. Crescimento Urbano, Saldos Migratórios e Atratividade Residencial dos Distritos da Cidade de São Paulo: 1980-2000. Paper presented at the XIII Encontro da Associação Brasileira de Estudos Populacionais, Ouro Preto, Minas Gerais, Brasil, de 4 a 8 de novembro.

Johnston, Ron, Michael Poulsen, and James Forrest. 2002. Rethinking the analysis of ethnic residential patterns: Segregation, isolation, or concentration thresholds in Auckland, New Zealand. Geographical Analysis 34(3): 245-261.

Kanaiupuni, Shawn M. 2000. "Reframing the Migration Question: An Analysis of Men,Women, and Gender in Mexico." Social Forces 78(4): 1311-1347.

Leme, Maria Cristina da Silva. 2003. O impacto da globalização em São Paulo e a precarização das condições de vida. Eure 24(87): 23-36.

Li, Wei. 1998. Los Angeles's Chinese ethnoburb: From ethnic service center to global economy outpost. Urban Geography 19(6): 502-517.

Logan, John R., Richard D. Alba, and Wenquan Zhang. 2002. Immigrant Enclaves and Ethnic Communities in New York and Los Angeles. American Sociological Review 67(2): 299-322.

Massey, Douglas. 1990. The Social and Economic Origins of Immigration. Annals of the American Academy of Political and Social Science 510: 60-72.

Massey, Douglas and Brendan P. Mullan. 1984. Processes of Hispanic and Black spatial assimilation. American Journal of Sociology 89: 836-871.

Massey, Douglas and Rene Zenteno. 1999. The Dynamics of Mass Migration. Proceedings of the National Academy of Sciences 96: 5328-5335.

Pacyga, Dominic A. 1995. Chicago's ethnic neighborhoods: The myth of stability and the reality of change. In Ethnic Chicago: A multicultural portrait, ed. Melvin G. 
Holli and Peter Jones: 604-617. Grand Rapids, MI: William B. Eerdmans Publishing Company.

Park, Robert E., Ernest W. Burgess, and Roderick D. McKenzie, ed. 1925. The city. Chicago: University of Chicago Press.

Pasternak, Suzana and Nelson Baltrusis. 2001. Um olhar sobre a habitação em São Paulo. São Paulo: Projeto FINEP/HABITARE.

Philpott, T.L. 1978. The slum and the ghetto: Neighborhood deterioration and middle class reform, Chicago, 1880-1930. New York: Oxford University Press.

Portes, Alejandro and Leif Jensen. 1987. What's an ethnic enclave? The case for conceptual clarity. American Sociological Review 54: 745-767.

Poulsen, Michael, Ron Johnston and James Forrest. 2001. Intraurban ethnic enclaves: introducing a knowledge-based classification method. Environment and Planning A 33: 2071-2082.

Ramos, Frederica Roman. 2002. Análise espacial de estruturas intra-urbanas: o caso de São Paulo. Dissertacao, Ministério da Ciência e Tecnologia, INPE, São José dos Campos.

Schor, Silvia Maria, Rinaldo Artes, and Valeria Cusinato Bomfim. 2003. Determinants of Spatial Distribution of Street People in the City of São Paulo. Urban Affairs Review 38(4): 592-602.

Torres, Haroldo de Gama, Eduardo Marques, Maria Paula Ferreira, and Sandra Bitar. 2002. Poverty and Space: Patterns of Segregation in São Paulo". Paper presented in the Workshop on Spatial Segregation and Urban Inequality in Latin America. Austin, Texas, November 15 and 16.

Ward, David. 1968. The emergence of central immigrant ghettoes in American cities: 1840-1920. Annals of the Association of American Geographers 58(4): 343-359.

White, Michael J., Robert F. Dymowski, and Shilian Wang. 1994. Ethnic neighbors and ethnic myths: An examination of residential segregation in 1910. In After Ellis Island: Newcomers and natives in the 1910 census, ed. Susan Cotts Watkins. New York: Russell Sage Foundation.

Wong, David W.S. 1998. Spatial Patterns of Ethnic Integration in the United States. Professional Geographer 50(1): 13-30.

.2003. Implementing Spatial Segregation Measures in GIS. Computers, Environment and Urban Systems 27: 53-70. 
Zhou, Min and John R. Logan. 1991. In and out of Chinatown: Residential mobility and segregation of New York City's Chinese. Social Forces 70: 387-407. 
Table 1 - Population of the Mesoregion of São Paulo by Migration Status

\begin{tabular}{lcc} 
& Frequency & Percent \\
\hline Short-term migrant & $3,663,317$ & 19.09 \\
Long-term migrant & $9,274,114$ & 48.33 \\
Non-migrant & $6,252,320$ & 32.58 \\
\hline Total & $19,189,751$ & 100.00 \\
\hline
\end{tabular}

Source: 2000 Brazilian Census, IBGE. 
Table 2 - Short-term Migrants by State of Birth, 2000

\begin{tabular}{lcc}
\hline State of Birth & Total & Percent \\
\hline São Paulo & 912,510 & 24.91 \\
Bahia & 755,591 & 20.63 \\
Pernambuco & 453,796 & 12.39 \\
Minas Gerais & 322,276 & 8.80 \\
Ceará & 207,105 & 5.65 \\
Paraíba & 164,184 & 4.48 \\
Alagoas & 156,461 & 4.27 \\
Paraná & 151,498 & 4.14 \\
Piauí & 136,307 & 3.72 \\
Maranhão & 61,130 & 1.67 \\
Sergipe & 59,558 & 1.63 \\
Rio Grande do Norte & 59,323 & 1.62 \\
Rio de Janeiro & 55,836 & 1.52 \\
Other countries & 54,445 & 1.49 \\
Rio Grando do Sul & 23,170 & 0.63 \\
Santa Catarina & 15,487 & 0.42 \\
Espírito Santo & 14,991 & 0.41 \\
Pará & 14,164 & 0.39 \\
Goiás & 13,322 & 0.36 \\
Mato Grosso do Sul & 12,758 & 0.35 \\
Mato Grosso & 7,533 & 0.21 \\
Distrito Federal & 4,781 & 0.13 \\
Amazonas & 2,704 & 0.07 \\
Tocantins & 1,577 & 0.04 \\
Rondônia & 1,406 & 0.04 \\
Acre & 702 & 0.02 \\
Amapá & 587 & 0.02 \\
Roraima & 115 & 0.00 \\
\hline Total & $3,663,317$ & 100.00 \\
\hline Source:2000 Brazilan Census & $B G E$ & \\
\hline
\end{tabular}

Source: 2000 Brazilian Census, IBGE. 
FIGURE 1

Flow of migrants to São Paulo from selected states in Brazil, 2000

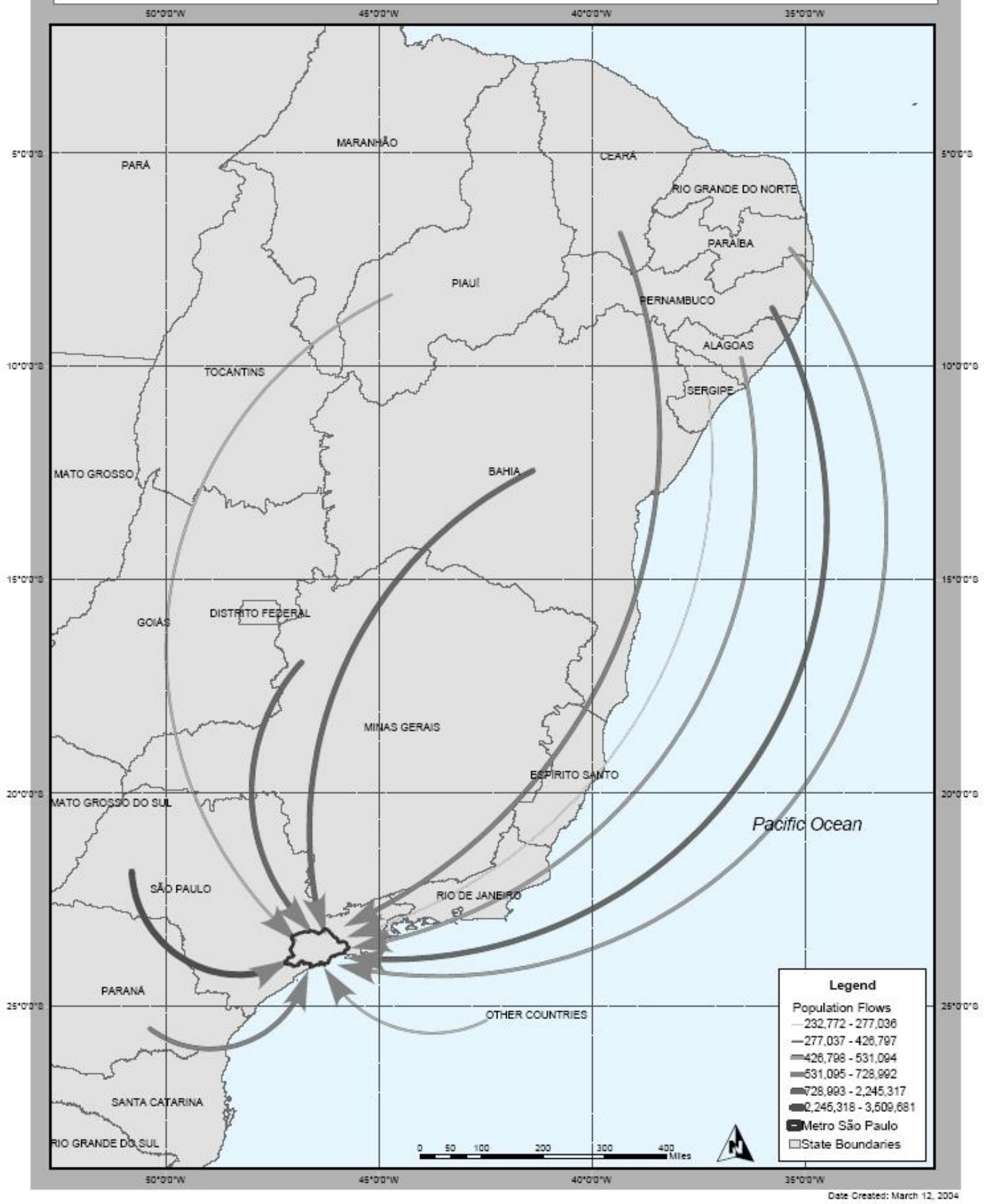


FIGURE 2

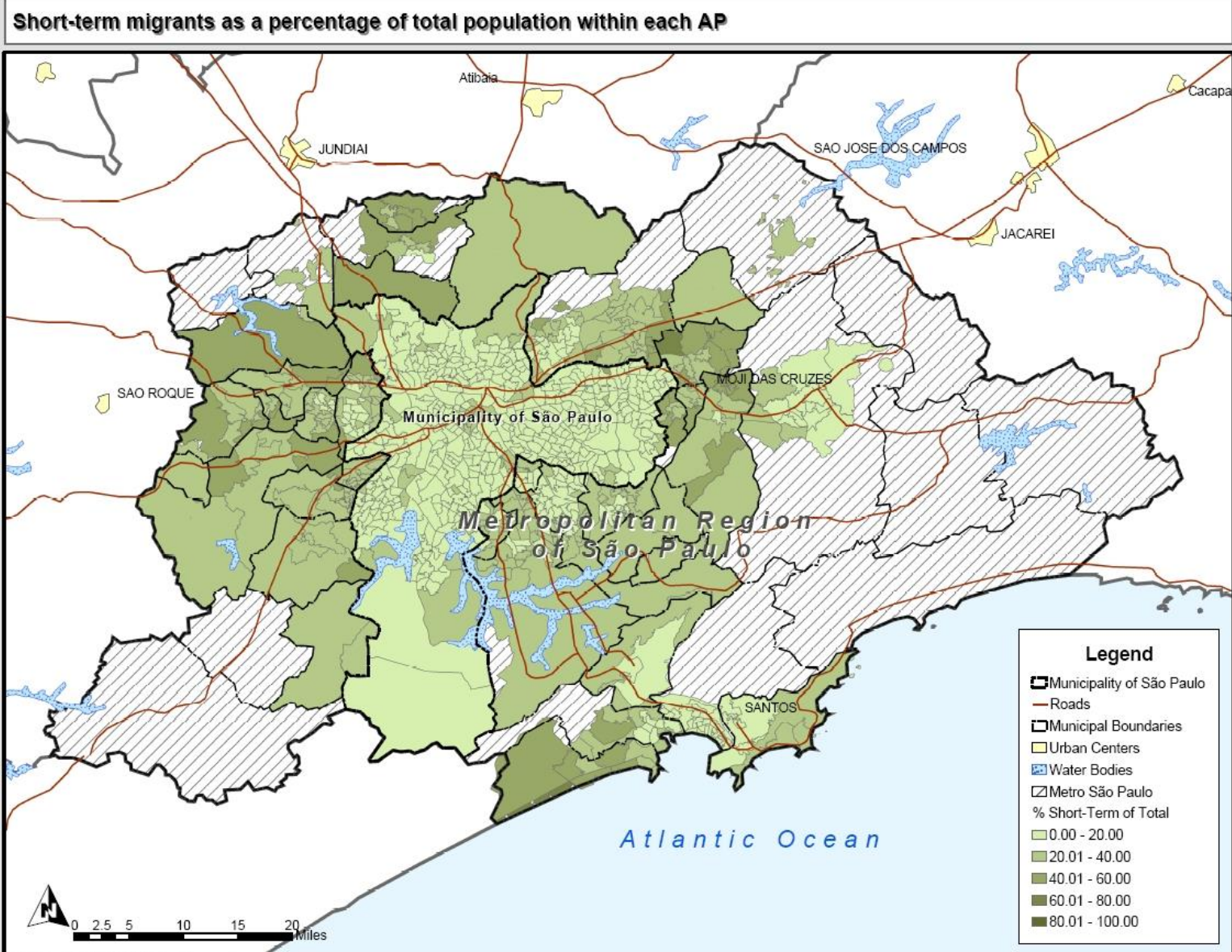

Date Created: February 20, 2004 
FIGURE 3

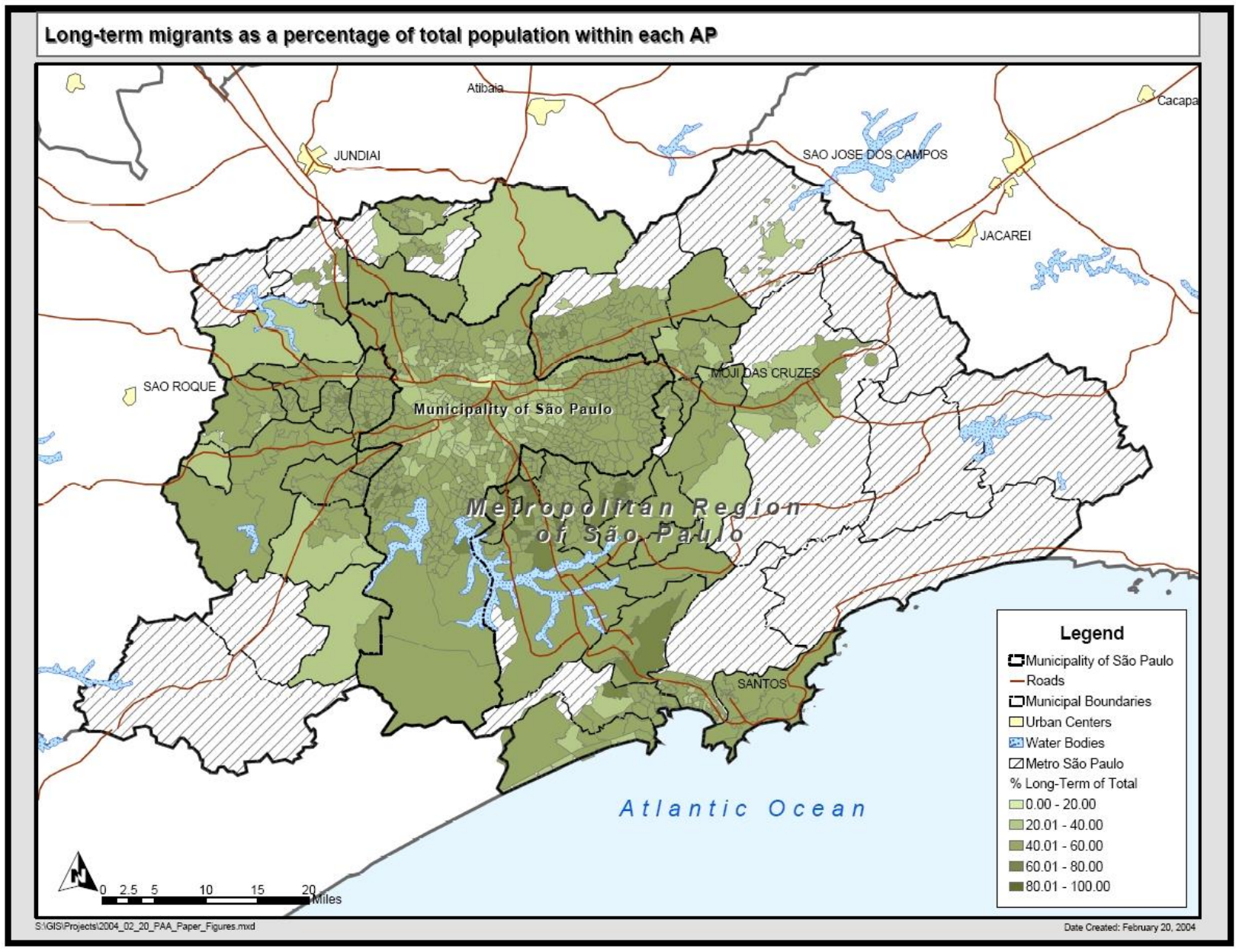




\section{FIGURE 4}

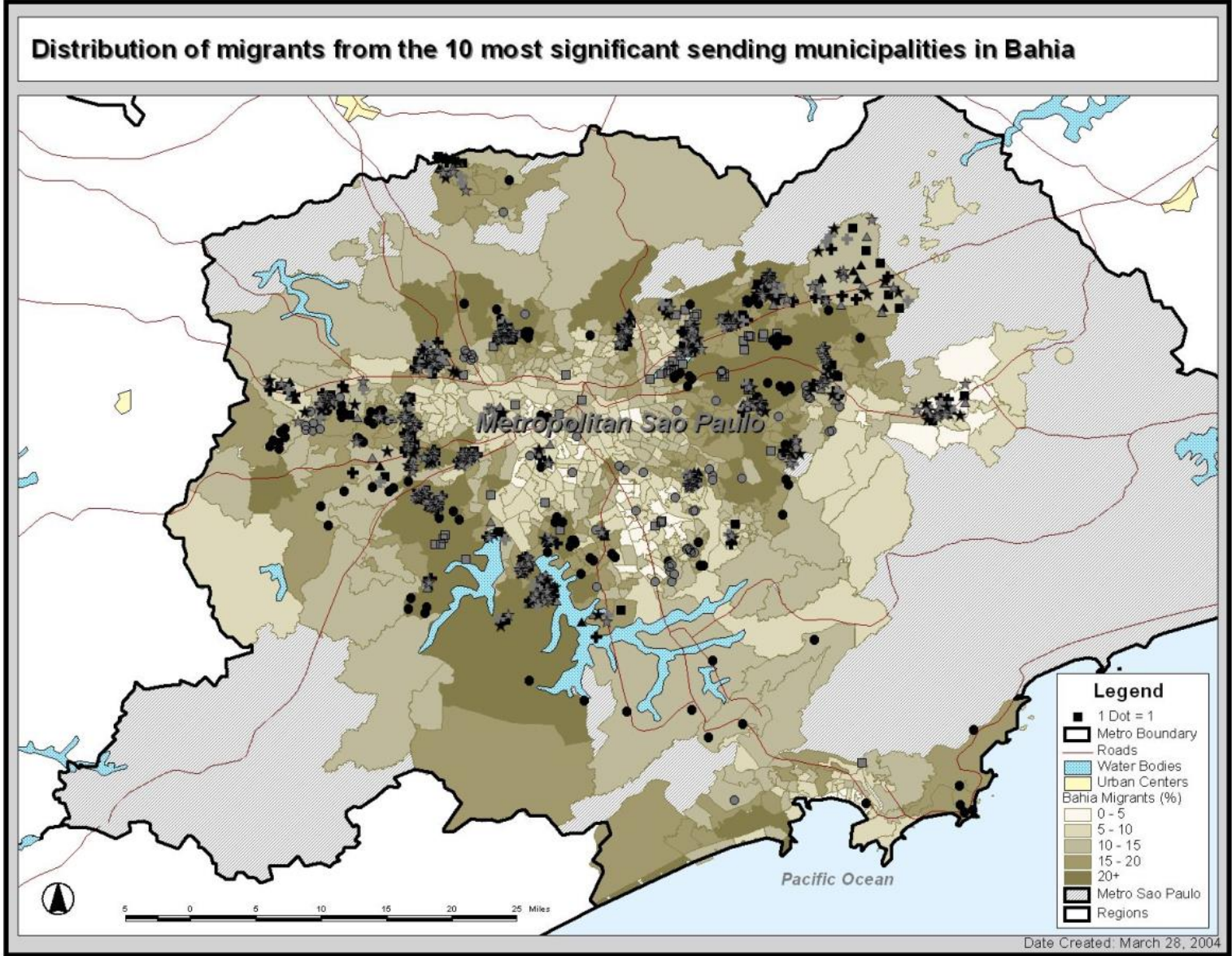




\section{FIGURE 5}

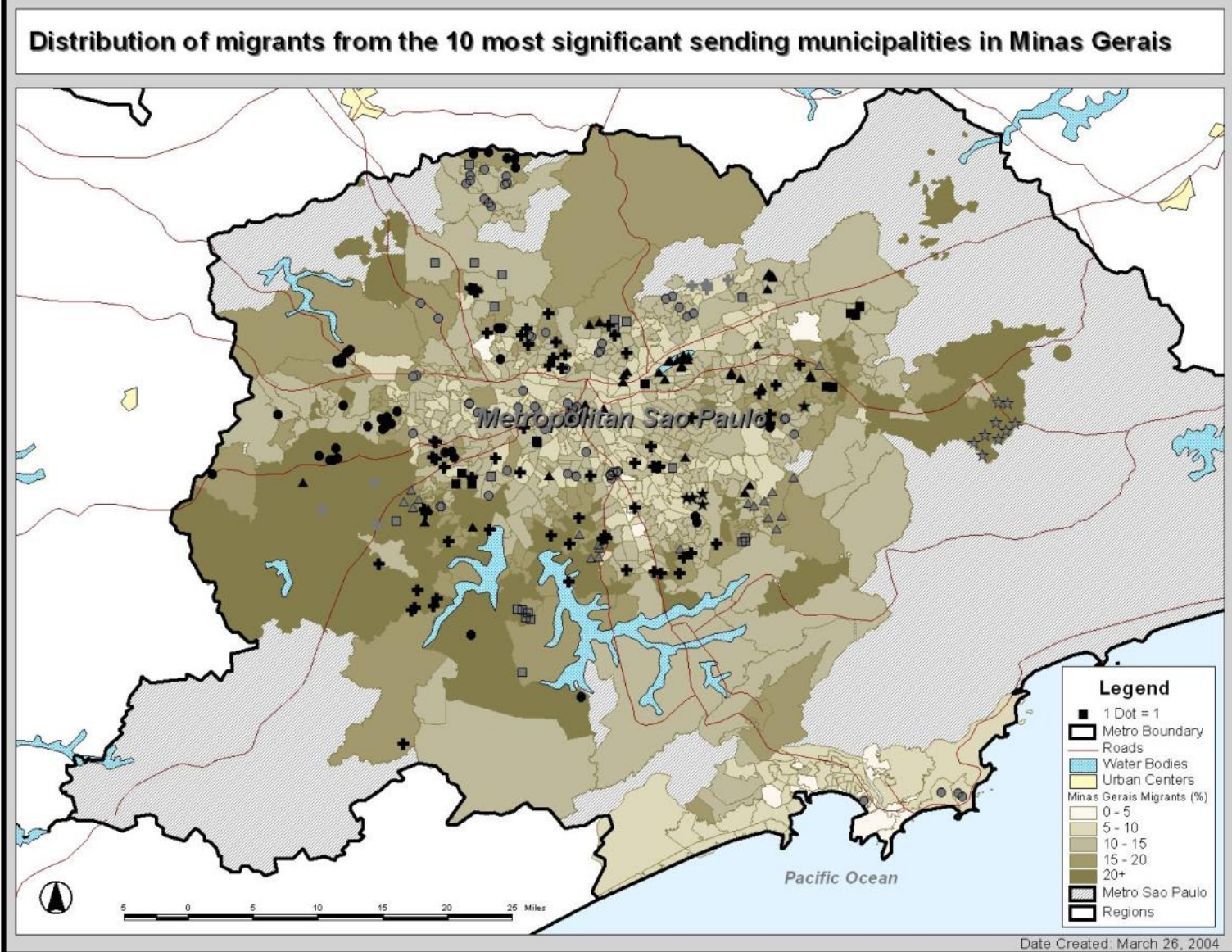




\section{FIGURE 6}

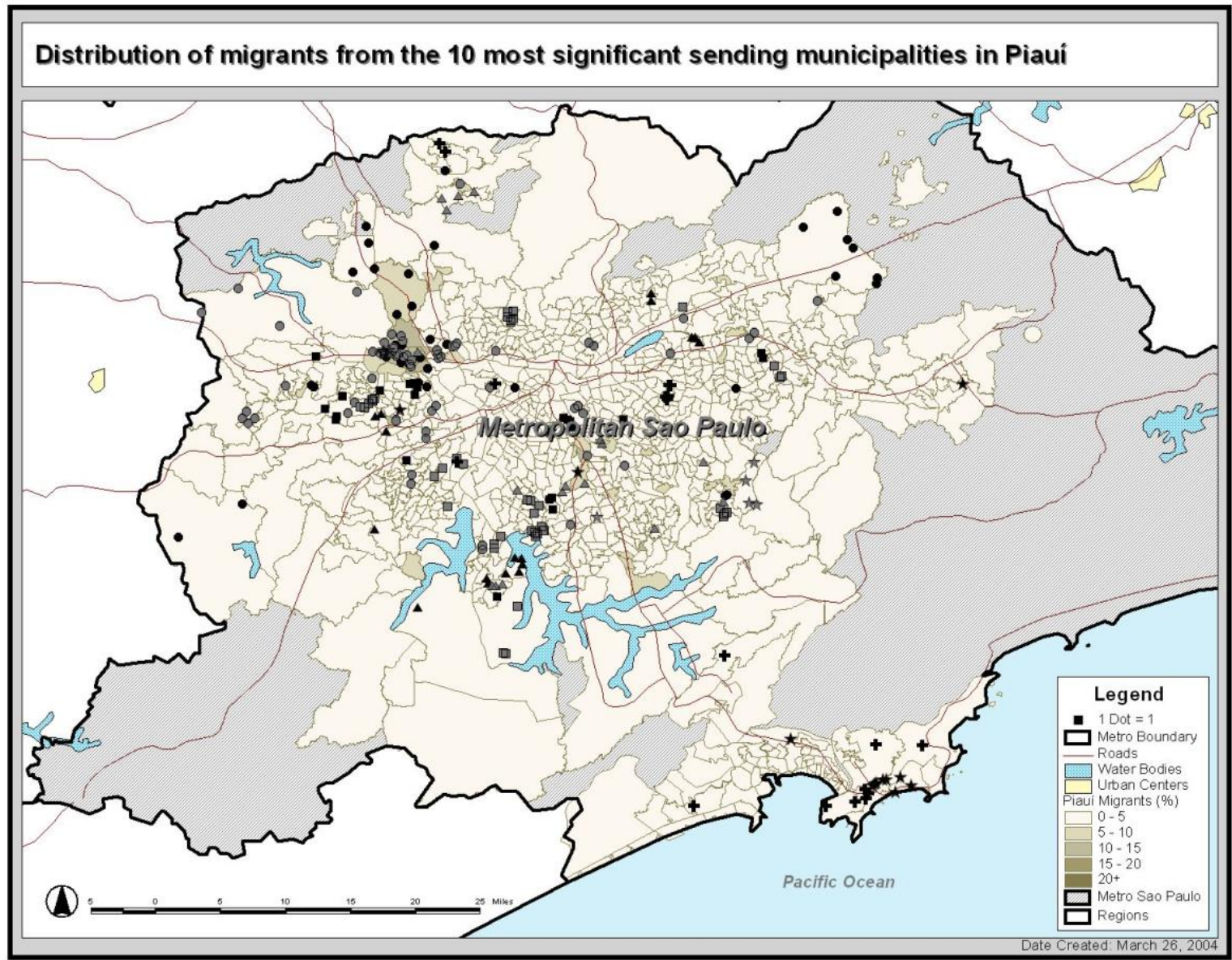


Table 3 - Segregation Measures, 2000

\begin{tabular}{|c|c|c|c|c|c|}
\hline & Dissimilarity & Exposure & Isolation & $\mathrm{D}(\mathrm{s})$ & $S$ \\
\hline \multicolumn{6}{|c|}{ Migrant Group vs. Remaining Population } \\
\hline BA - Bahia & 0.24 & 0.11 & 0.89 & 0.22 & 0.24 \\
\hline MG - Minas Gerais & 0.19 & 0.08 & 0.92 & 0.18 & 0.18 \\
\hline PE - Pernambuco & 0.23 & 0.08 & 0.92 & 0.22 & 0.09 \\
\hline CE - Ceará & 0.24 & 0.03 & 0.97 & 0.24 & 0.13 \\
\hline PR - Paraná & 0.18 & 0.03 & 0.97 & 0.18 & 0.15 \\
\hline PI - Piaui & 0.34 & 0.02 & 0.98 & 0.33 & 0.27 \\
\hline SE - Sergipe & 0.35 & 0.01 & 0.99 & 0.34 & 0.60 \\
\hline OC - Other Countries & 0.45 & 0.02 & 0.98 & 0.45 & 0.31 \\
\hline PB - Paraiba & 0.23 & 0.03 & 0.97 & 0.23 & 0.13 \\
\hline $\mathrm{AL}$ - Alagoas & 0.23 & 0.02 & 0.98 & 0.23 & 0.14 \\
\hline \multicolumn{6}{|l|}{ Migrant Group vs. Other Migrants } \\
\hline BA - Bahia & 0.21 & 0.16 & 0.84 & 0.19 & 0.13 \\
\hline MG - Minas Gerais & 0.16 & 0.12 & 0.88 & 0.15 & 0.19 \\
\hline PE - Pernambuco & 0.19 & 0.11 & 0.89 & 0.18 & 0.13 \\
\hline CE - Ceará & 0.21 & 0.05 & 0.95 & 0.20 & 0.16 \\
\hline PR - Paraná & 0.15 & 0.05 & 0.95 & 0.15 & 0.15 \\
\hline PI - Piaui & 0.30 & 0.02 & 0.98 & 0.30 & 0.28 \\
\hline SE - Sergipe & 0.34 & 0.02 & 0.98 & 0.34 & 0.59 \\
\hline OC - Other Countries & 0.52 & 0.03 & 0.97 & 0.51 & 0.36 \\
\hline PB - Paraiba & 0.20 & 0.04 & 0.96 & 0.19 & 0.09 \\
\hline $\mathrm{AL}$ - Alagoas & 0.20 & 0.04 & 0.96 & 0.20 & 0.11 \\
\hline \multicolumn{6}{|c|}{ Short-term Migrants vs. Long-term Migrants } \\
\hline $\mathrm{BA}$ - Bahia & 0.24 & 0.31 & 0.69 & 0.20 & 0.17 \\
\hline MG - Minas Gerais & 0.28 & 0.18 & 0.82 & 0.25 & 0.22 \\
\hline PE - Pernambuco & 0.26 & 0.28 & 0.72 & 0.22 & 0.20 \\
\hline CE - Ceará & 0.27 & 0.28 & 0.72 & 0.22 & 0.18 \\
\hline PR - Paraná & 0.32 & 0.20 & 0.80 & 0.27 & 0.28 \\
\hline PI - Piaui & 0.30 & 0.37 & 0.63 & 0.21 & 0.16 \\
\hline SE - Sergipe & 0.38 & 0.21 & 0.79 & 0.29 & 0.20 \\
\hline OC - Other Countries & 0.39 & 0.12 & 0.88 & 0.33 & 0.28 \\
\hline PB - Paraiba & 0.29 & 0.29 & 0.71 & 0.23 & 0.19 \\
\hline $\mathrm{AL}$ - Alagoas & 0.32 & 0.29 & 0.71 & 0.25 & 0.19 \\
\hline \multicolumn{6}{|l|}{ Summary Measures } \\
\hline Migrants vs. Non-Migrants & 0.27 & 0.62 & 0.38 & 0.24 & 0.20 \\
\hline Short-term vs. Long-Term Migrants & 0.24 & 0.26 & 0.74 & 0.21 & 0.22 \\
\hline Source: 2000 Brazilian Census, IBGE & & & & & \\
\hline
\end{tabular}


Table 4: Concentration of Migrant Groups in São Paulo by AP, 2000

\begin{tabular}{|c|c|c|c|c|c|c|c|c|c|}
\hline \multirow[b]{2}{*}{ Migrant state of origin } & \multicolumn{9}{|c|}{ Threshold Bands } \\
\hline & $0-5$ & $5-10$ & $10-15$ & $15-20$ & $20-25$ & $25-30$ & $30-35$ & $35-40$ & Totals \\
\hline \multicolumn{10}{|c|}{ Percent of total population } \\
\hline BA - Bahia & 4.35 & 19.10 & 29.03 & 30.64 & 12.44 & 3.82 & 0.63 & 0.00 & 100.00 \\
\hline MG - Minas Gerais & 7.47 & 48.52 & 31.78 & 10.85 & 1.38 & 0.00 & 0.00 & 0.00 & 100.00 \\
\hline PE - Pernambuco & 11.08 & 44.38 & 34.77 & 8.50 & 0.25 & 1.02 & 0.00 & 0.00 & 100.00 \\
\hline PR - Paraná & 73.13 & 26.60 & 0.27 & 0.00 & 0.00 & 0.00 & 0.00 & 0.00 & 100.00 \\
\hline CE - Ceará & 60.32 & 36.86 & 2.82 & 0.00 & 0.00 & 0.00 & 0.00 & 0.00 & 100.00 \\
\hline PB - Paraíba & 84.74 & 12.93 & 1.15 & 0.52 & 0.67 & 0.00 & 0.00 & 0.00 & 100.00 \\
\hline $\mathrm{AL}$ - Alagoas & 90.34 & 9.66 & 0.00 & 0.00 & 0.00 & 0.00 & 0.00 & 0.00 & 100.00 \\
\hline PI - Piauí & 94.21 & 3.57 & 2.22 & 0.00 & 0.00 & 0.00 & 0.00 & 0.00 & 100.00 \\
\hline SE - Sergipe & 93.40 & 5.23 & 1.16 & 0.21 & 0.00 & 0.00 & 0.00 & 0.00 & 100.00 \\
\hline OC - Other Countries & 52.41 & 39.85 & 5.53 & 1.40 & 0.00 & 0.81 & 0.00 & 0.00 & 100.00 \\
\hline \multicolumn{10}{|c|}{ Percent of migrant population } \\
\hline BA - Bahia & 0.58 & 6.85 & 17.58 & 25.89 & 22.98 & 16.17 & 8.15 & 1.80 & 100.00 \\
\hline MG - Minas Gerais & 0.68 & 25.02 & 46.28 & 18.68 & 8.26 & 1.09 & 0.00 & 0.00 & 100.00 \\
\hline PE - Pernambuco & 3.29 & 26.67 & 39.87 & 25.76 & 3.73 & 0.50 & 0.17 & 0.00 & 100.00 \\
\hline PR - Paraná & 34.10 & 64.04 & 1.86 & 0.00 & 0.00 & 0.00 & 0.00 & 0.00 & 100.00 \\
\hline CE - Ceará & 29.81 & 65.25 & 4.60 & 0.34 & 0.00 & 0.00 & 0.00 & 0.00 & 100.00 \\
\hline PB - Paraíba & 62.65 & 35.89 & 1.17 & 0.19 & 0.10 & 0.00 & 0.00 & 0.00 & 100.00 \\
\hline $\mathrm{AL}$ - Alagoas & 65.97 & 33.71 & 0.32 & 0.00 & 0.00 & 0.00 & 0.00 & 0.00 & 100.00 \\
\hline PI - Piauí & 90.45 & 7.13 & 2.25 & 0.17 & 0.00 & 0.00 & 0.00 & 0.00 & 100.00 \\
\hline SE - Sergipe & 92.06 & 6.15 & 1.27 & 0.37 & 0.15 & 0.00 & 0.00 & 0.00 & 100.00 \\
\hline OC - Other Countries & 32.68 & 62.33 & 3.41 & 1.20 & 0.18 & 0.14 & 0.05 & 0.00 & 100.00 \\
\hline \multicolumn{10}{|l|}{ Number of Districts } \\
\hline BA - Bahia & 152 & 275 & 228 & 161 & 50 & 14 & 2 & 0 & 882 \\
\hline MG - Minas Gerais & 165 & 493 & 171 & 48 & 5 & 0 & 0 & 0 & 882 \\
\hline PE - Pernambuco & 286 & 376 & 181 & 35 & 1 & 3 & 0 & 0 & 882 \\
\hline PR - Paraná & 751 & 130 & 1 & 0 & 0 & 0 & 0 & 0 & 882 \\
\hline CE - Ceará & 706 & 167 & 9 & 0 & 0 & 0 & 0 & 0 & 882 \\
\hline PB - Paraíba & 829 & 49 & 2 & 1 & 1 & 0 & 0 & 0 & 882 \\
\hline $\mathrm{AL}$ - Alagoas & 846 & 36 & 0 & 0 & 0 & 0 & 0 & 0 & 882 \\
\hline PI - Piauí & 849 & 23 & 10 & 0 & 0 & 0 & 0 & 0 & 882 \\
\hline SE - Sergipe & 845 & 29 & 7 & 1 & 0 & 0 & 0 & 0 & 882 \\
\hline OC - Other Countries & 736 & 132 & 11 & 2 & 0 & 1 & 0 & 0 & 882 \\
\hline
\end{tabular}

Source: 2000 Brazilian Census, IBGE. 


\section{Endnotes}

i Throughout the paper, we will use the terms mesoregion of São Paulo and São Paulo interchangeably to mean the mesoregion designated by the Brazilian Census that includes forty-four (44) different municipalities and a total population of nearly twenty (20) million.

ii We don't explicate the entire matrix of in-migration and out-migration here. In effect, we are only describing half of the story - but this is primarily because we are interested in the spatial outcomes of migrants living within the São Paulo mesoregion. For an excellent examination of the recent characteristics of internal migration to/from São Paulo, see Baeninger 2001 and Cunha 2001. These two articles examine the role of São Paulo in both the historical concentration and more recent deconcentration of Brazil's population.

iii More than 55,000 short-term migrants arrived from overseas. These foreign-born migrants are an interesting case. As Table 3 indicates, they are the most highly segregated group of migrants. When mapped out, these migrants are highly clustered in the core of the city and demonstrate a residential patterning dramatically different from Brazilian-born migrants. This phenomenon is worthy of further study, and will be explored in future research.

iv Another problem is that software (ArcView 8.0) that creates the dot density maps randomly insert dots within each areal unit, in this case the AP. So, even though dots may appear to be either clustered and/or dispersed in an individual AP, we have no way of knowing how close and/or far apart the individual migrants are from one another in real geographic space. The migrants could be living in the same house, the same apartment complex, on the same block, or on opposite sides of the AP.

$\checkmark$ The $\mathrm{D}(\mathrm{s})$ and $\mathrm{S}$ indices were calculated using an ArcView 3.x extension provided courtesy of David W.S. Wong. The development of the ArcView extension was partially supported by the National Institute of Health/Child Health and Human Development (NICHD) under the National Institute of Health (NIH) grant number 1 R03 HD38292-01 awarded to David W.S. Wong. 